\title{
ИННОВАЦИОННАЯ ДЕЯТЕЛЬНОСТЬ СОВРЕМЕННЫХ ПРЕДПРИЯТИЙ
}

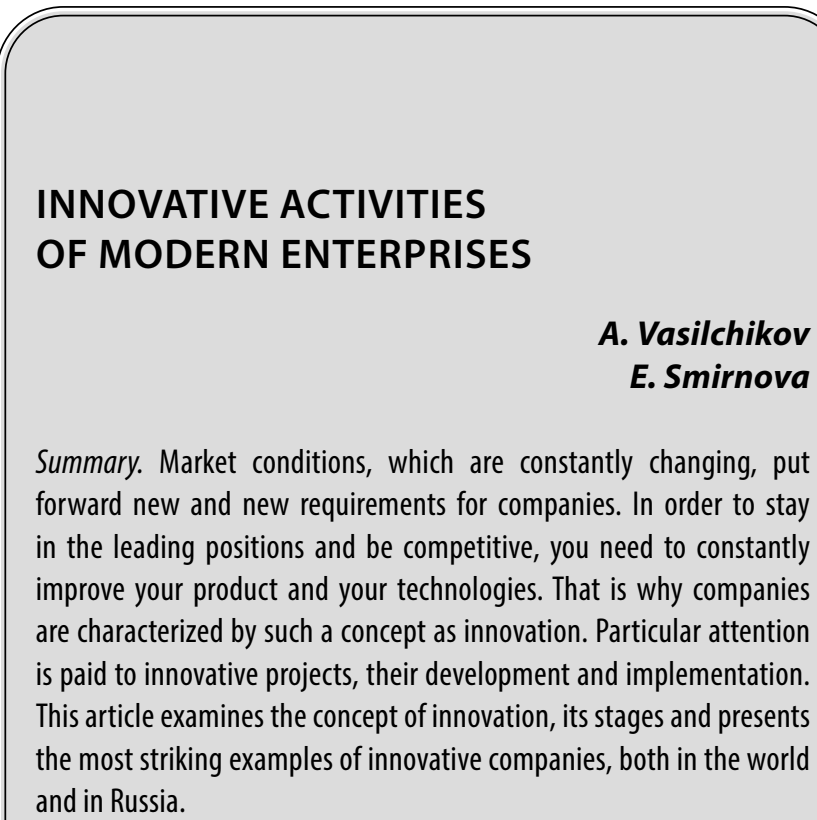

Keywords: innovation, innovative project, innovation, investment.

\author{
Васильчиков Алексей Валерьевич \\ Д.э.н., профессор, Самарский государственный \\ технический университет \\ vav309@yandex.ru \\ Смирнова Елизавета Александровна \\ Самарский национальный исследовательский \\ университет имени академика С.П. Королёва \\ sheglowa.eliz@yandex.ru
}

Аннотация. Рыночные условия, которые постоянно меняются, выдвигают к компаниям новые и новые требования. Для того, чтобы оставаться на лидирующих позициях и быть конкурентоспособными, необходимо постоянно совершенствовать свой товар и свои технологии. Именно поэтому для компаний характерно такое понятие, как инновационная деятельность. Особое внимание уделяется инновационным проектам, их разработке и реализации. В настоящей статье рассмотрено понятие инновационной деятельности, ее этапы и представлены самые яркие примеры инновационных компаний, как в мире, так и в России.

Ключевые слова: инновация, инновационный проект, новаторство, инвестиции.

Рассмотрим в каких случаях необходимо проводить оценку эффективности инновационного проекта.

Так, например, это характерно для компании, в которой уже существует достаточное количество инновационных проектов, но они направлены на различные области реализации, именно здесь необходимо решить приоритетность финансирования возможных проектов [2]. Также, на начальном этапе разработки, могут возникнуть несколько альтернативных проектов и предложений, тогда приходится решать вопрос о выборе самого перспективного. Ну, и конечно же, на заключительном этапе, когда необходим анализ проекта в целом, для определения его результативности. На данном этапе идет сравнение плановых и фактических показателей проекта. Именно на основании данных показателей, можно судить об эффективности проекта [3]. Так, если все цели, которые были поставлены в ходе разработки и реализации проекта, достигнуты, то проект можно считать эффективным.

На начальном этапе инновационного проекта, наиболее сложно определить систему критериев отбора 


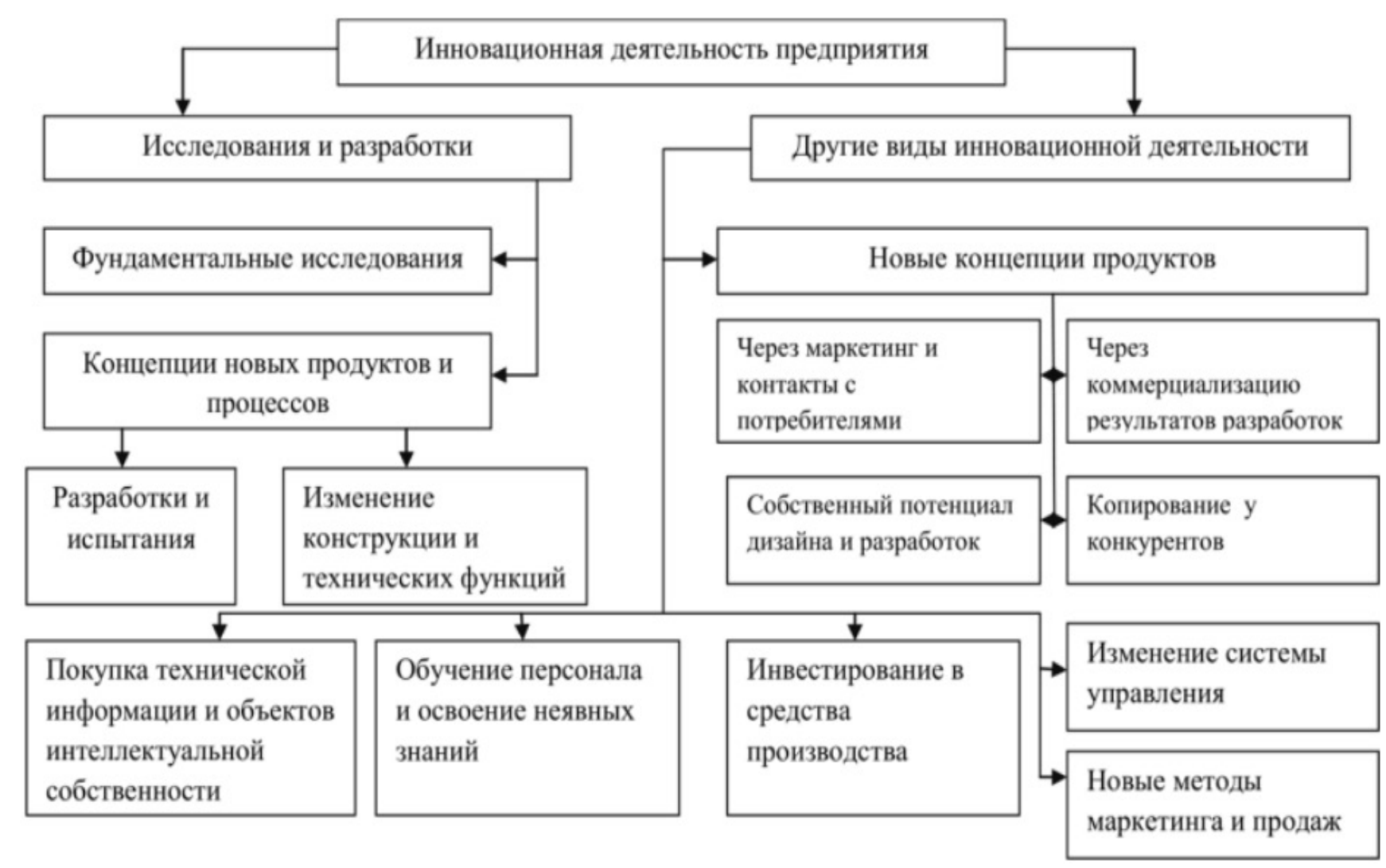

Рис. 1. Схема инновационной деятельности компании

инноваций. Стоит отметить, что в современной практике, до сих пор не достигнуто единой концепции оценки эффективности инновационного проекта.

Понятия инновационного и инвестиционного проекта очень схожи между собой. Сам по себе инновационный продукт подразумевает вклад денежных средств в разработку. Но есть некоторые черты, которые позволяют отличить проекты между собой.

Например, целью инновационного проекта является выпуск новейшего товара или технологии. Сам по себе проект имеет временную неопределенность в то время, как инвестиционный уже подразумевает сколько будет срок его выполнения. Конечно же, срок у инновационного проекта зачастую значительно больше, чем инвестиционного, так как проходит много стадий от задумки до выполнения.

Отбор инновационного проекта это одна из самых сложных и серьезных стадий. На данном этапе необходимо определить действительно стоящий проект, который в дальнейшем пойдет в разработку. Здесь возникают вопросы оценки и критерии отбора, которые в современном инновационном менеджменте не установлены окончательно, а также, стоит отметить, что для разработчиков и заказчиков приоритетные критерии будут разные [4].

Основным стимулом создания инновационного проекта - является обновление товаров на рынке, так как для них характерен моральный износ. Необходимо определить именно такой продукт, выпуск которого уже не актуален на рынке и именно поэтому специалисты в крупных компаниях постоянно проводят мониторинг рынка. При выявлении таких товаров или технологий, руководителям компании необходимо быстро принять решение о новых разработках, пока не опередят конкуренты.

Новаторская деятельность характерная для небольших компаний, в которых сложно выделять средства для инновационных проектов на постоянной основе.

В компании, для которой характерна разработка и внедрение инноваций, создается отдел, который возглавляет сотрудник, имеющий достаточный опыт для выявления устаревших продуктов и технологий. Сами сотрудники такого отдела, должны направлять свои знания и опыт на выявление перспективных проектов, которые не имеют аналогов у конкурентов и будут первыми на рынке. Стоит отметить, что в начале иннова- 
ционный продукт, будет потреблять ресурсы и только через определенное время сможет принести прибыль компании.

Если инновация будет удачной и интересной на рынке, будет пользоваться спросом, то она способна вернуть затраты и окупить себя несколько раз. Если фактические показатели не дотягивают до плановых, то инновационный проект должен признаться неудачным.

Стоит отметить, что не всегда компания создает отдел по реализации инновационных проектов внутри компании, но и прибегает к сторонним организациям. Появляется такое понятие, как венчуры, это как раз структуры, которые ведут инновационные проекты. К внутренним венчурам относятся обособленные отделы, которые созданы для разработки нового продукта и функционируют независимо в компании. Внешние венчуры, это компании, которые специализируются на рискованных финансовых вложениях в исследования и научные разработки. Для таких компаний характерны определенные финансовые риски. Таким компаниям государство предоставляет ряд налоговых льгот и финансовую поддержку, в виде различных субсидий и грантов на развитие. Так как государство также заинтересовано в инновационных разработках компаний на территории своей страны [5]. На рисунке ниже представлена схема инновационной деятельности компании.

Большинство современных компаний не создают отдельные центры для разработки инновационных проектов. Рассмотрим некоторые российские компании, которые имеют такие площадки.

Так, например, знаменитый X5 Retail Group имеет центр инноваций ритейла. Главной задачей имеющихся департаментов является генерирование идей, которые в будущем можно использовать в реализации успешных проектов компании. Естественно, главной целью является повышение финансовой устойчивости компании и устойчивая позиция лидера на рынке.

В компании «Мегафон», которая является крупным оператором сотовой связи, имеется так называемая «технологическая песочница», это площадка, на которой рассматриваются различные стартапы и инновационные решения, которые в дальнейшем утверждаются или отклоняются. Так, за время работы площадки утверждено более 100 пилотных проектов компании.

Банк «Открытие» также не остался в стороне. На его площадке разработан сервис стратегической аналитики. Именно здесь производят анализ предложенных инновационных проектов и идей, которые направлены на развитие бизнеса и IT-подразделений, а также генерируются идеи, которые в дальнейшем развиваются и внедряют заказчики инноваций.

Стоит отметить, что наличие центра инноваций у компании не показывает ее инновационность. Необходимо не только собирать новые идеи, но также их прорабатывать и внедрять для дальнейшей работы. Также следует изучать сильные и слабые стороны, прорабатывать проблемы инновационного проекта, убеждать руководителей на внедрение проекта. Подобных центров инноваций в российских компаниях очень мало, в основном они развернуты на площадках крупных организаций, и в большинстве случаях имитируют свою деятельность.

Одной из самых крупных и узнаваемых компаний мира является американская корпорация Apple. Ha ceгодняшний день является одной из самых инновационных компаний, которая перешла за рамки простого бренда и стала символом. Стоит отметить, что компания создает не просто инновации, а задает тренды современности. О компании и ее создателе написаны множество научных трудов, а ее продукты известны во всем мире. Каждый год компания внедряет различные инновации, которые перерастают в революционную новинку. Ежегодные обновления операционной системы, разработка и выведение на рынок различных гаджетов, которые несут в себе массу инновационных решений, например, внедрение опции мультизадачности системы и сверхпродуктивный режим сохранения заряда батареи. Также, Apple представляет инновационные разработки в различных областях, так, ярким примером является собственная платежная система, или водосберегающая насадка для душа [6].

Не менее крупной и известной компанией в мире является еще одна американская корпорация, Google. Всем известная, как самая масштабная поисковая интернет-система. Google не отстает от конкурентов в части инновационных проектов. Именно поэтому постоянно проводится работа по поиску новых идей и проектов. Инновационные проекты компании не перестают удивлять не только конкурентов, но и общество в целом. Так, например, одним из масштабных проектов Google, является проект «Космический лифт», который предполагает доставку населения с планеты Земля в космос. Или, например, проект по созданию электронной таблетки, также кажется нереальным и не выполнимым. По задумке данного проекта, созданная таблетка сможет с точностью определять диагноз больного человека. Возможно, сейчас это кажется что-то из области фантастики, но компания продолжает свою работу над подобными проектами и возможно в будущем они принесут свои результаты [7]. 
Американская корпорация Microsoft, также не может остаться в стороне без внимания. Один из крупнейших игроков на рынке, а также генератор инновационных идей, которые внедряет компания. Заслуги основателя компании Билла Гейтса перед современным обществом трудно переоценить, так как именно его инновационный проект в виде «Windows» перевернул мир. Компания стала одним из мировых лидеров, большая заслуга принадлежит именно эффективному менеджменту и развитию инноваций, так как новые разработанные технологии сразу становились популярными во всем мире [8].

Одним из прорывов в цифровой области стал продукт компании «Meta» - «WhatsApp». Сервис, который заменил привычное для всех SMS сообщение через сотовых операторов. Сегодня, это один из удобных сервисов мгновенного обмена информацией среди различных поколений.

Все вышеперечисленные компании совершили прорыв в области цифровизации и продолжают разрабатывать свои новые инновационные проекты. Не стоит забывать и о других отраслях, так, например, компания Bayer, которая является одним из крупных разработчиков и поставщиков в области химии и фармацевтики. Известные разработки компании - это биоактивные средства, заменяющие химические препараты; прогресс в лечение многих болезней; образовательные проекты по профилактике ряда заболеваний.

Стоит отметить, что в мире большое количество компаний, которые совершают прорыв в области инноваций и представляют в наше пользование свои разработанные продукты. Предприятия во всем мире стараются разработать новые качественные продукты, использую инновационные подходы для достижения успеха.

Российские компании также не отстают от своих зарубежных коллег в области инновационной деятельности.

Так, одним из самых ярких примеров является компания «Яндекс». Компания всем известна, как одна из крупнейших поисковых систем. Но на ее площадке разработаны, такие сервисы, как «Яндекс Еда», «Яндекс Такси», «Яндекс Маркет», «Яндекс Путешествия» и многие другие. Компания не перестает удивлять своими новыми проектами [9].

Также одним из крупных инновационных проектов, является проект сотового оператора «Мегафон». Компания нацелена разработать низкоорбитальную спутниковую систему для высокоскоростной передачи данных. Основной целью проекта является увеличение скорости передачи данных. Для реализации данного проекта, компания готова вложить 6 млрд. рублей [10].

Крупный игрок в нефтяной отрасли - компания «Роснефть», также не остается в стороне. У компании разработана программа инновационного развития ПАО «НК «Роснефть» на 2016-2020 гг. с перспективой до 2030 года. Данная Программа была одобрена и утверждена Межведомственной комиссией по технологическому развитию президиума Совета при Президенте Российской Федерации по модернизации экономики и инновационному развитию России. Инновационные проекты направлены на развитие высоких технологий энергетической компании, улучшение экономических показателей, а также повышение энергоэффективности производства по добыче нефти и газа; соблюдение международных стандартов экологической безопасности [11].

Также, примером может быть компания МТС, стратегия этой компании нацелена на расширение своих услуг населению, создания облачных сервисов и внедрение телевидения в свою линейку.

Конечно же, это одни из немногих компаний России, которые могут быть примером разработки и внедрения инновационных проектов $[12,13]$.

Как уже говорилось выше, сам по себе инновационный проект должен нести прибыль компании и ее устойчивость на рынке среди конкурентов. Разрабатывая и внедряя инновационный проект, каждая компания должна понимать, что без определенного багажа опыта и знаний, идея может быть провальной вплоть до банкротства, так как подобные проекты несут в себе большие финансовые затраты. Неквалифицированные кадры, отсутствие необходимых методик и подходов, слабая команда менеджеров, отсутствие мотивации сотрудников - такие проблемы предприятия могут отрицательно сказаться на разработке проекта. Если компания столкнулась с подобными проблемами, то для начала нужно их решить, а потом переходить к инновационному управлению в компании, чтобы не потерпеть финансовые потери.

В заключении стоит сказать, что разработка и реализация инновационного проекта - это сложный и серьезный процесс для любого предприятия, независимо от положения на рынке и среди конкурентов. Каждое предприятие желает добиться максимальной выгоды и эффективности от своего продукта. Но как известно, лидером на рынке окажется та компания, которая первая предложит новейший продукт на рынке, которому нет аналогов. Компании, которые реализуют инновации меняют не только свое будущее, но и будущее всего мира. 


\section{ЛИТЕРАТУРА}

1. Герасимов К.Б. Управление инновациями в строительных фирмах // Вестник НГИЭИ. — 2020. — № 8(111). — С. 104-116.

2. Николаева 0.Ю. Обзор современного инструментария финансового обеспечения инновационной деятельности предприятия // Вопросы экономических наук. - 2020. - № 2(102).- - С. 23-25.

3. Стуканов Д.В. Проблемы реализации инновационной деятельности отечественными предприятиями на современном этапе // Экономика и управление: проблемы, решения.— 2019.— - Т. 14.— № 3.—C. 111-115.

4. Марголин А.М., Быстряков А.Я. Экономическая оценка инвестиций.—- М.: ТАНДЕМ, Экмос, 2019.

5. Ендовицкий Д.А. Комплексный анализ и контроль инвестиционной деятельности: методология и практика. — М.: Финансы и статистика, 2019. — 350 c.

6. История компании Apple [Электронный ресурс] — URL: https://www.rbc.ru/photoreport/01/04/2016/56fe4e859a7947a4d1b919ce

7. История компании Google [Электронный ресурс] — URL: https://about.google/int//ru/

8. История компании Microsoft [Электронный ресурc] — URL: https://www.microsoft.com/ru-ru

9. История компании Яндекс [Электронный ресурс] — URL: https://yandex.ru/

10. История компании Мегафон [Электронный ресурс] — URL: https://corp.megafon.ru/about/history/

11. История компании ПАО НК РОСНЕФТЬ [Электронный ресурc] — URL: https://www.rosneft.ru/

12. Ендовицкий Д.А. Инвестиционный анализ в реальном секторе экономики.-М.: Финансы и статистика, 2018.

13. Маренков Н.Л. Инвестиции.—Ростов н/Д: «Феникс», 2018. - 448 с.

с Васильчиков Алексей Валерьевич ( vav309@yandex.ru ), Смирнова Елизавета Александровна ( sheglowa.eliz@yandex.ru ).

Журнал «Современная наука: актуальные проблемы теории и практики»

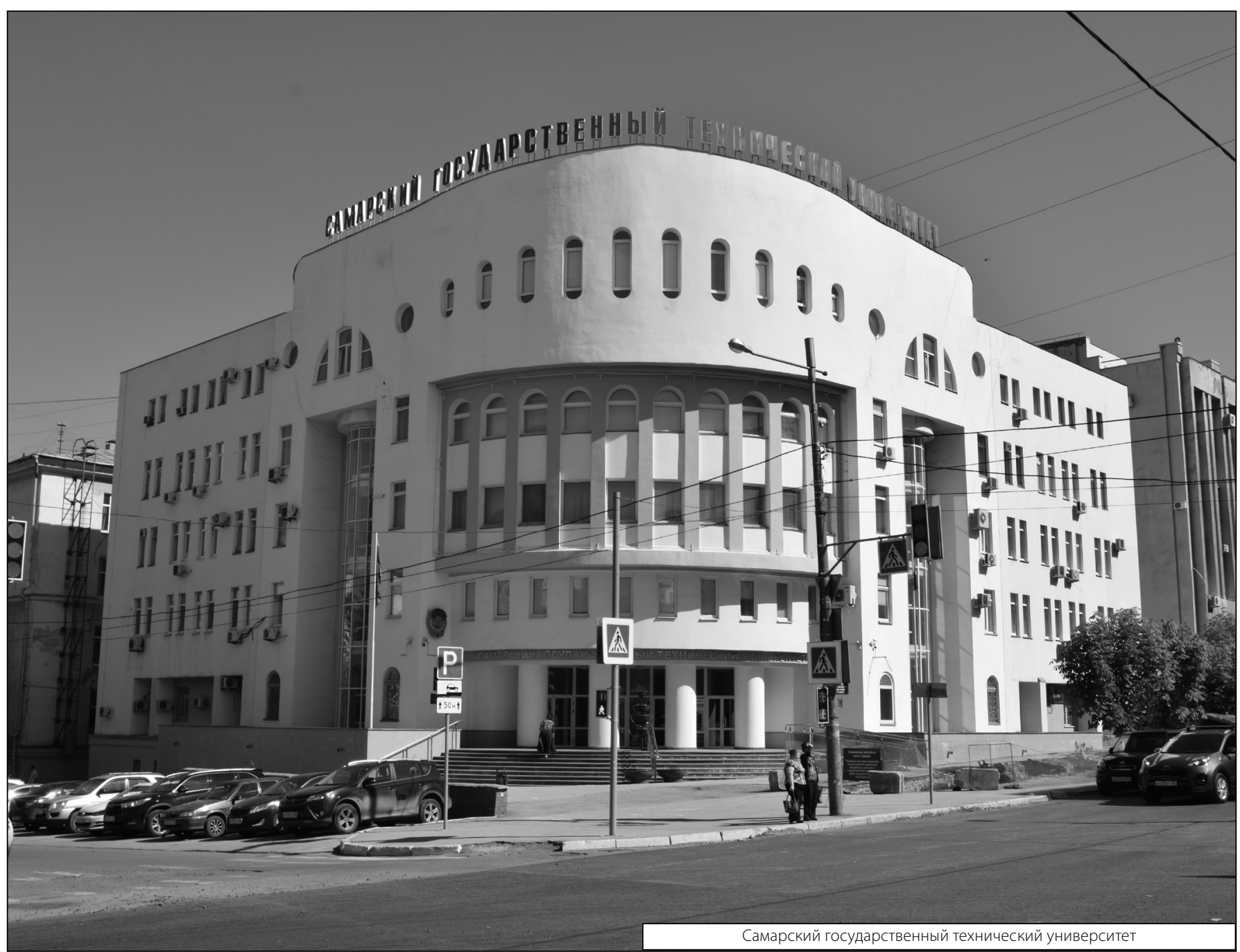

